\title{
Delay in diagnosis of pulmonary tuberculosis in low-and middle-income settings: systematic review and meta- analysis
}

Fentabil Getnet ${ }^{1 *}$, Meaza Demissie ${ }^{2}$, Nega Assefa ${ }^{3}$, Bizatu Mengistie ${ }^{3}$ and Alemayehu Worku ${ }^{4}$

\begin{abstract}
Background: Assessment of delays in seeking care and diagnosis of tuberculosis is essential to evaluate effectiveness of tuberculosis control programs, and identify programmatic impediments. Thus, this review of studies aimed to examine the extent of patient, health system, and total delays in diagnosis of pulmonary tuberculosis in low- and middle- income countries.

Methods: It was done following the Preferred Reporting Items for Systematic Reviews and Meta-Analyses. Electronic databases were searched to retrieve studies published from 2007 to 2015 including Pubmed central, Springer link, Hinari and Google scholar. Searching terms were pulmonary tuberculosis, health care seeking, health care seeking behavior, patient delay, diagnostic delay, health system delay, provider delay, and doctor delay. Retrieved studies were systematically reviewed and summarized using Comprehensive Meta-analysis software.

Results: Forty studies involving 18,975 patients qualified for systematic review, and 14 of them qualified for meta-analysis. The median diagnostic delay ranged from 30 to 366.5 days [IQR $=44-77.8$, with a 4-199 days $[\mathrm{IQR}=15-50]$ and $2-128.5$ days [IQR $=12-34]$ due to patient and health system delays, respectively. The meta-analysis showed $42 \%$ of pulmonary tuberculosis patients delayed seeking care by a month or more; uneducated patients [pooled $\mathrm{OR}=1.5,95 \% \mathrm{Cl}=1.1-1.9$ ] and those who sought initial care from informal providers [pooled $\mathrm{OR}=3$, $95 \% \mathrm{Cl}=2.3-3.9]$ had higher odds of patient delay.

Conclusion: Delay in diagnosis is still a major challenge of tuberculosis control and prevention programs in low- and middle- income settings. Efforts to develop new strategies for better case-finding using the existing systems and improving patients' care seeking behavior need to be intensified.
\end{abstract}

Keywords: Patient delay, Health system, Diagnosis delay, Pulmonary tuberculosis

\section{Background}

Tuberculosis (TB) causes an estimated 10.4 million cases and 1.7 million deaths globally, with the heaviest toll in Low- and Middle-Income countries (LMICs) [1]. The main strategies to control TB are early diagnosis and prompt treatment initiation [2]. Passive case-finding is the main approach currently applied by most national TB control programs (NTPs) [3]. The term "passive"

\footnotetext{
*Correspondence: b.infen4ever@gmail.com

${ }^{1}$ Department of Public Health, College of Medicine and Health Sciences, Jigjiga University, PO Box = 1020, Jigjiga, Ethiopia

Full list of author information is available at the end of the article
}

implies that TB case detection entirely relies on people with TB symptoms presenting themselves to the health facilities [2]. Successful case detection also relies on health systems capacity to promptly diagnose and commence treatment [4].

However, this passive process has not been as effective as it should be in many LMICs [5]. The effectiveness of the passive case-finding system is influenced by many factors including patient health seeking behavior, the efficiency and competence of healthcare workers, and the quality of laboratory facilities [6, 7]. Failure to timely detect and treat TB could worsen illness severity, 
prolongs patient suffering, increases the risk of patient death, and facilitates the transmission of the disease (if smear positive pulmonary TB) to close contacts [8-10].

Delay in diagnosis and treatment initiation of TB has remained unacceptably high especially among high burden countries $[6,7]$. Related systematic reviews were reported on the subject matter in 2008 [6] and 2010 particularly from Sub-Saharan Africa [11]. These reviews included all studies done on delay in diagnosis and treatment of TB regardless of the disease type. However, most NTPs promote healthcare seeking for presumptive cases with pulmonary symptoms [12]. Plus, pulmonary tuberculosis (PTB) patients are responsible for disease transmission (specially smear positive patients), and longer delays facilitate the spreading to close contacts [13]. On the other side, extra-pulmonary TB (ЕРTB) forms are not easily detectable using clinical and laboratory examinations. As a result, delay will inflate if EPTB patients are included [2].

More importantly, massive efforts were implemented during the era of Stop TB Strategy (2006-2015) to substantially reduce the global burden of TB by 2015 through universal access to diagnosis and treatment regardless of socio-economic barriers [14]. A periodic conduct of systematic review is warranted to incorporate lessons learned from such massive and dynamic TB control programs to improve the practice of early detection and initiation of treatment. Therefore, this systematic review and meta-analysis was conducted to summarize the extent of delays and identify factors that influenced prompt detection and treatment of PTB in LMICs where access or utilization of TB services has not been optimal as required. We have also examined the median delay differences between Sub-Saharan Africa and Other LMICs.

\section{Methods}

We systematically reviewed studies reported from LMICs to summarize delays in diagnosis of PTB patients and to identify factors contributing to high extents of delay. We thought such a specific study on delay in diagnosis of PTB patients would be more beneficial from programmatic and interventional perspectives. Meta-analysis principles were applied to combine numeric data on delays and affecting factors. We followed the Preferred Reporting Items for Systematic Reviews and Meta-Analyses (PRISMA) [15] as a standard guideline.

\section{Search strategy}

Various electronic databases were searched to retrieve relevant published studies using Boolean searching technique [16]. We used 'AND' and 'OR'to connect key search terms to retrieve studies from Pubmed. The search terms we used include pulmonary tuberculosis, diagnosis delay, patient delay, health system delay, provider delay, doctor delay, delayed consultation, health care seeking, and health care seeking behavior (Table 1). In addition, we searched other web-based sources including Springer link, Hinari, and Google scholar, though not standard sources, to retrieve studies that are not indexed in Pubmed.

We searched each source twice. The first author (FG) conducted the primary searching of studies from sources listed above and then the co-author (NA) independently and blindly conducted it again using similar searching technique, databases and terms. All the potential studies identified by both authors were set for screening and selection process. We contacted 5 authors via email for unpublished studies and raw data but none responded to our requests.

Table 1 Pudmed search strategies

\begin{tabular}{|c|c|c|}
\hline S. No. & Search terms or strategies & Remarks \\
\hline 1. & Pulmonary tuberculosis AND diagnosis Delay* & \multirow{12}{*}{$\begin{array}{l}\text { Example of search detail (1): ("tuberculosis, pulmonary"[MeSH Terms] } \\
\text { OR ("tuberculosis"[All Fields] AND "pulmonary"[All Fields]) OR "pulmonary } \\
\text { tuberculosis"[All Fields] OR ("pulmonary"[All Fields] AND "tuberculosis"[All } \\
\text { Fields])) AND (("diagnosis"[Subheading] OR "diagnosis"[All Fields] OR } \\
\text { "diagnosis"[MeSH Terms]) AND delay[All Fields]) } \\
\text { *indicates truncation }\end{array}$} \\
\hline 2. & Pulmonary tuberculosis AND delayed consultation* & \\
\hline 3. & Pulmonary tuberculosis AND patient delay* & \\
\hline 4. & Pulmonary tuberculosis AND healthcare seeking & \\
\hline 5. & Pulmonary tuberculosis AND healthcare seeking behavior & \\
\hline 6. & Pulmonary tuberculosis AND health system delay* & \\
\hline 7. & Pulmonary tuberculosis AND provider delay* & \\
\hline 8. & Pulmonary Tuberculosis AND doctor delay* & \\
\hline 9. & Patient delay OR health system delay* & \\
\hline 10. & Patient delay OR provider delay* & \\
\hline 11 & Patient delay OR doctor delay* & \\
\hline 12. & $\begin{array}{l}\text { Tuberculosis AND Diagnosis delay OR delayed consultation OR } \\
\text { patient delay OR health system delay OR provider delay OR } \\
\text { doctor delay }\end{array}$ & \\
\hline
\end{tabular}




\section{Inclusion/exclusion criteria}

We included studies that were reported in English, conducted in low and middle income countries, published between 2007 and 2015 (era of Stop TB strategy), with any observational study design (cross-sectional, case-control, or cohort studies), and those which fully or partially measured diagnosis delays (patient delay/health system delay/total diagnosis delay). With respect to the study participants, we included studies on pulmonary TB patients who sought healthcare themselves and above 15 years old regardless of smear type (positive/negative/ unknown) and treatment category (new/retreatment). Studies done on PTB and EPTB patients were considered when data were presented for PTB patients separately. However, we excluded studies that were on presumptive TB cases (formerly called 'suspects') and special groups (e.g. HIV, MDR), qualitative in design, and community based studies which applied active case-finding strategies.

Further inclusion criteria were used for Meta-analysis from eligible studies for systematic review. These included studies that categorized patient delay using 15 , 21 or 30 days as cut-off points and reported cross tabulations and/or odds ratio/relative risk of explanatory variables.

\section{Selection of studies}

Eligible studies were selected using the pre-specified inclusion/exclusion criteria. Initially, the studies were searched and potential articles were identified using the title and then abstract by two reviewers (FG and NA) independently. Following identification of potential studies, FG made the final selection through thorough review of full articles including the study design, participants, outcome variable studied (delay), and publication year. Co-authors (NA and BM) closely supervised the selection process.

\section{Quality assessment}

All included studies were assessed for their scientific quality usingquality assessment tools developed by the National Collaborating Center for Environmental Health [17] and National Institute of Health (NIH) National Heart, Lung and Blood Institute [18].

The quality of each study was assessed using 4 parameters: 1) defined study population, 2) representativeness of participants and low non-response rate, 3) comparability of analysis groups and outcome ascertainment, and 4) adjusted analysis to control confounding. Each parameter was rated as 1 if 'Yes' and 0 if 'No'. Then the scores were added and the quality of each studywas leveled as good (if 3 or 4 'yes's), fair (2 'yes's) and poor (if 0 or 1 yes). Fair and good quality studies were considered as satisfying quality (Table 2). The quality of all included
Table 2 quality assessment result of the studies included in the systematic review and meta-analysis

\begin{tabular}{|c|c|c|c|c|c|c|}
\hline Study & Study Design & A & B & C & $\mathrm{D}$ & Total score \\
\hline Alavi et al. 2015 [45] & CS & 1 & 0 & 1 & 1 & 3 \\
\hline Asefa et al. 2014 [27] & CS & 1 & 1 & 1 & 1 & 4 \\
\hline Aye et al. 2010 [46] & $\mathrm{RC}$ & 1 & 0 & 1 & 1 & 4 \\
\hline Basnet et al. 2009 [47] & CS & 1 & 1 & 1 & 1 & 4 \\
\hline Behera et al. 2013 [48] & CS & 1 & 1 & 1 & 1 & 4 \\
\hline Belkina et al. 2014 [44] & CS & 1 & 1 & 1 & 1 & 4 \\
\hline Biya et al. 2010 [49] & CS & 1 & 0 & 1 & 1 & 3 \\
\hline Buregyeya et al. 2014 [50] & CS & 1 & 0 & 1 & 1 & 3 \\
\hline Cambanis et al 2007 [51] & CS & 1 & 1 & 1 & 1 & 4 \\
\hline Deponti et al. 2013 [52] & CS & 1 & 0 & 1 & 1 & 3 \\
\hline Ekinci et al. 2014 [22] & CS & 1 & 0 & 1 & 1 & 3 \\
\hline Ford et al. 2009 [21] & CS & 1 & 0 & 1 & 1 & 3 \\
\hline Gebeyehu et al. 2014 [34] & CS & 1 & 0 & 1 & 1 & 3 \\
\hline Gosoniu et al. 2008 [19] & CS & 1 & 0 & 1 & 1 & 3 \\
\hline Gosoniu et al. 2008 [19] & CS & 1 & 0 & 1 & 1 & 3 \\
\hline Gosoniu et al. 2008 [19] & CS & 1 & 0 & 1 & 1 & 3 \\
\hline Huong et al. 2007 [30] & CS & 1 & 1 & 1 & 1 & 4 \\
\hline Hussen et al. 2012 [35] & CS & 1 & 0 & 1 & 1 & 3 \\
\hline Jurcev-Savicevic et al. 2013 [53] & CS & 1 & 1 & 1 & 1 & 4 \\
\hline Kansiime et al. 2013 [54] & CS & 1 & 1 & 1 & 1 & 4 \\
\hline Li et al. 2012 [55] & CS & 1 & 1 & 1 & 1 & 4 \\
\hline Maamari et al. 2008 [25] & CS & 1 & 1 & 1 & 1 & 4 \\
\hline Maciel et al. 2010 [56] & CS & 1 & 1 & 1 & 1 & 4 \\
\hline Maior et al. 2012 [57] & CS & 1 & 1 & 1 & 1 & 4 \\
\hline Makwakwa et al. 2014 [58] & CS & 1 & 1 & 1 & 1 & 4 \\
\hline Mesfin et al. 2009 [29] & CS & 1 & 1 & 1 & 1 & 4 \\
\hline Mfinanga et al. 2008 [59] & CS & 1 & 1 & 1 & 1 & 4 \\
\hline Mohamed et al. 2013 [36] & CS & 1 & 1 & 1 & 1 & 4 \\
\hline Nasehi et al. 2012 [60] & CS & 1 & 1 & 1 & 1 & 4 \\
\hline Ngadaya et al. 2009 [61] & CS & 1 & 1 & 1 & 1 & 4 \\
\hline Ngangro et al. 2012 [62] & CS & 1 & 1 & 1 & 1 & 4 \\
\hline Pradhan et al. 2010 [43] & CS & 1 & 1 & 1 & 1 & 4 \\
\hline Rabin et al. 2013 [63] & CS & 1 & 1 & 1 & 1 & 4 \\
\hline Sabawoon et al. 2011 [31] & CS & 1 & 0 & 1 & 1 & 3 \\
\hline Saifodine et al. 2013 [37] & CS & 1 & 1 & 1 & 1 & 4 \\
\hline Sendagire et al. 2010 [64] & CS & 1 & 1 & 1 & 1 & 4 \\
\hline Takarinda et al. 2015 [32] & CS & 1 & 1 & 1 & 1 & 4 \\
\hline Tamhane et al. 2012 [23] & CS & 1 & 0 & 1 & 1 & 3 \\
\hline Ukwaja et al. 2013 [24] & CS & 1 & 1 & 1 & 1 & 4 \\
\hline Woith et al. 2014 [65] & CS & 1 & 0 & 1 & 1 & 3 \\
\hline Yimer et al. 2015 [66] & CS & 1 & 1 & 1 & 1 & 4 \\
\hline
\end{tabular}

$\mathrm{CS}$; refers to cross-sectional and $\mathrm{RC}$; refers to retrospective cohort. The columns: A. Study population defined; B. representativeness of participants and low non-response rate; C. Comparability of analysis groups and outcome ascertainment; D. analysis to control confounding Rating: $(0=$ No and $1=$ Yes). This format was adapted from a similar review done in China [67] 
Table 4 The median delay (days) in diagnosis of pulmonary tuberculosis in low and middle income countries other than Sub-Saharan Africa, 2007 to $2015(n=22)$

\begin{tabular}{|c|c|c|c|c|c|c|c|c|c|}
\hline First Author & Country & $\begin{array}{l}\text { Publication } \\
\text { Year }\end{array}$ & Design & Setting & $\begin{array}{l}\text { Sample } \\
\text { size }\end{array}$ & Patient Delay & $\begin{array}{l}\text { Health System } \\
\text { Delay }\end{array}$ & Total Delay & $\begin{array}{l}\text { Ref. } \\
\text { No }\end{array}$ \\
\hline Huong & Vietnam & 2007 & CS & TB units & 2087 & 21 & 7 & 30 & {$[30]$} \\
\hline Maamari & Syria & 2008 & CS & TB centers & 800 & $31(\dot{X}=52.7)$ & $11.7(\dot{X}=24.8)$ & $55(\dot{X}=77.6)$ & [25] \\
\hline Gosoniu & Bangladesh & 2008 & CS & Clinics, HC & 102 & * & * & 60 & [19] \\
\hline Gosoniu & India & 2008 & $\mathrm{CS}$ & Health centers, Clinics & 127 & * & * & 74 & [19] \\
\hline Basnet & Nepal & 2009 & CS & Hospital \&HC & 307 & 50 & 18 & 60 & [47] \\
\hline Ford & Peru & 2009 & CS & Hospital \& Health post & 108 & 61 & * & * & {$[21]$} \\
\hline Maciel & Brazil & 2010 & CS & Primary PHF & 304 & 76 & 30 & 110 & [56] \\
\hline Aye & Tajikistan & 2010 & $\mathrm{RC}$ & Hospital, HC, clinics & 204 & 21.5 & 16 & 53 & [46] \\
\hline Pradhan & India & 2010 & CS & DOTs centers & 266 & $6(\dot{X}=30)$ & $31(\dot{X}=61)$ & $37(\dot{X}=91)$ & [43] \\
\hline Sabawoon & Afghanistan & 2011 & CS & Hospital \& clinic & 122 & $199(\dot{X}=205.2)$ & $128.5(\dot{X}=150)$ & $366.5(\dot{X}=356)$ & [31] \\
\hline $\mathrm{Li}$ & China & 2012 & CS & TB clinics & 323 & $10(\dot{X}=31)$ & * & * & [55] \\
\hline Nasehi & Iran & 2012 & CS & Hospital, clinics & 5702 & $*$ & * & 59 & {$[60]$} \\
\hline Tamhane & India & 2012 & CS & Health center & 150 & 15 & 31 & * & [23] \\
\hline Behera & India & 2013 & CS & Tertiary hospital & 204 & $16(\dot{X}=32.97)$ & $39(\dot{X}=60.46)$ & $43(\dot{X}=75.7)$ & [48] \\
\hline Rabin & Georgia & 2013 & CS & TB diagnostic centers & 247 & $23.5(\dot{X}=56.2)$ & $14(\dot{X}=33.7)$ & $59.5(\dot{X}=89)$ & {$[63]$} \\
\hline Deponti & Brazil & 2013 & CS & Tertiary hospital & 153 & 30 & 18 & 60 & {$[52]$} \\
\hline Jurcev-Savicevic & Croatia & 2013 & CS & Hospital & 241 & * & 15 & * & [53] \\
\hline Woith & Russia & 2014 & CS & TB clinics & 105 & 30 & * & * & [65] \\
\hline Ekinci & Turkey & 2014 & CS & Referral hospital & 136 & $12(\dot{X}=30.5)$ & $29(\dot{X}=48.7)$ & $54(\dot{X}=82.2)$ & [22] \\
\hline Alavi & Iran & 2015 & CS & Health Center & 139 & * & * & $48(\dot{X}=73)$ & {$[45]$} \\
\hline Belkina & Uzbekistan & 2014 & CS & Hospitall & 538 & 27 & 7 & 50 & [44] \\
\hline Maior & Brazil & 2012 & CS & TB clinic & 199 & 56 & 14 & 70 & [57] \\
\hline
\end{tabular}

Key: * Value not obtainable

$\dot{X}$ : Mean value

CS: Cross-sectional

HC: Health center

PHF: Public health facility

RC: Retrospective cohort

Table 3 The median delay (days) in diagnosis of pulmonary tuberculosis in Sub-Saharan Africa, 2007 to 2015 ( $n=19)$

\begin{tabular}{|c|c|c|c|c|c|c|c|c|c|}
\hline First Author & Country & $\begin{array}{l}\text { Publication } \\
\text { Year }\end{array}$ & Design & Setting & $\begin{array}{l}\text { Sample } \\
\text { Size }\end{array}$ & $\begin{array}{l}\text { Patient } \\
\text { Delay }\end{array}$ & $\begin{array}{l}\text { Health System } \\
\text { Delay }\end{array}$ & Total Delay & $\begin{array}{l}\text { Ref. } \\
\text { No }\end{array}$ \\
\hline Cambanis & Cameroon & 2007 & CS & Hospital & 243 & 15 & $*$ & $*$ & [51] \\
\hline Mfinanga & Tanzania & 2008 & CS & Hospital, HC\& dispensaries & 639 & $14(\dot{X}=37.4)$ & * & * & [59] \\
\hline Gosoniu & Malawi & 2008 & CS & Health centers, clinics & 100 & * & * & 33.5 & [19] \\
\hline Mesfin & Ethiopia & 2009 & CS & Hospital \& HC & 924 & 30 & * & * & [29] \\
\hline Ngadaya & Tanzania & 2009 & CS & Hospital, HC,TB dispensary & 206 & 62 & * & $90(\dot{X}=125.5)$ & [61] \\
\hline Biya & Nigeria & 2010 & CS & Hospital & 160 & 30 & * & * & [49] \\
\hline Sendagire & Uganda & 2010 & CS & Public health facility & 253 & 28 & 28 & 56 & [64] \\
\hline Hussen & Ethiopia & 2012 & CS & Hospital \& HC & 129 & 63 & 34 & 97 & [35] \\
\hline Ngangro & Chad & 2012 & CS & Hospital & 286 & 15 & 36 & 57.5 & [62] \\
\hline Ukwaja & Nigeria & 2013 & CS & Hospital & 450 & 56 & 21 & 77 & [24] \\
\hline Kansiime & Uganda & 2013 & CS & Referral hospital & 266 & $*$ & 9 & * & [54] \\
\hline Saifodine & Mozambique & 2013 & CS & Hospital and $\mathrm{HC}$ & 622 & 61 & 62 & 150 & [37] \\
\hline Mohamed & Sudan & 2013 & CS & TB management unit & 292 & $4(\dot{X}=27.2)$ & * & * & [36] \\
\hline Makwakwa & Malawi & 2014 & CS & Hospital & 588 & 14 & 59 & 80 & [58] \\
\hline Gebeyehu & Ethiopia & 2014 & CS & Hospital \&HC & 153 & 28 & * & * & [34] \\
\hline Asefa & Ethiopia & 2014 & CS & Health center & 328 & 30 & 7 & 37 & [27] \\
\hline Buregyeya & Uganda & 2014 & CS & Hospital and $\mathrm{HC}$ & 158 & 30 & 77 & 112 & [50] \\
\hline Yimer & Ethiopia & 2015 & CS & Hospital \&HC & 231 & 21 & $*$ & * & [66] \\
\hline Takarinda & Zimbabwe & 2015 & CS & Hospitals, clinics, PHF & 383 & 28 & 2 & 30 & [32] \\
\hline
\end{tabular}

Key: * indicates data not available 
studies was assessed by first author (FG), followed by immediate and independent crosschecking by two co-authors (NA and BM). Discrepancies were solved through mutual understanding.

\section{Data extraction}

Excel spreadsheet was used to extract available data on the name of first author, country where the study was conducted, publication year, type of health-care facility (study setting), study design, sample size, and median and/or mean delays (patient, health system and total) in days. Data from a study by Gosoniu et al. that involved 3 countries (Bangladesh, India and Malawi) was extracted separately for each country [19]. Delays reported in weeks were transformed into days by a multiple of 7 (Tables 3 and 4). The predictor variables that have statistically significant association with patient, health system and total diagnosis delay were also extracted (Table 5).

Further data were extracted on the event (delay) among exposure categories and/or odds ratio for metaanalysis. Health system and total delays were not considered for meta-analysis because of lack of clear cutoff values. The studies we reviewed did not use standard cutoff value to categorize patient delays. Therefore, we used the WHO recommended cutoff points (15 and 21 days) [20] and the commonly used 30 days by numerous studies. There was also considerable variability in the way studies categorized explanatory variables, thus variables categorized in the same way were considered for meta-analysis. The final explanatory variables we came up with, therefore, were sex, residence, educational status, first care seeking from informal healthcare provider, and HIV status.

\section{Definition of terms}

The definitions of terms in included studies were critically reviewed. Different studies used different terms to describe patient, health system, and diagnosis delays. For instance, some studies described patient delay as TB test delay or TB test seeking delay [21] and patients' application interval [22]. Health system delay is also referred to as doctor delay or provider delay [22-24]. Most studies used the term 'total delay' as the time until the diagnosis while some until treatment. In such a case, we took the delay until diagnosis [25-29]. Accordingly, delay terms have been defined as follows:

Table 5 Summary of risk factors for delay in diagnosis in low and middle income countries, 2007 to 2015

\begin{tabular}{|c|c|c|}
\hline Patient delay & Health System Delay & Total Delay \\
\hline $\begin{array}{l}\text { Socio-demographic: } \\
\text { Poor literacy [21, 24, 28, 29, 35, 62], Rural } \\
\text { residence [29, 34, 35], Urban residence } \\
{[24,36,37] \text {, Older age [24], long distance to }} \\
\text { the nearest HF [24, 30-32, 35, 59], Being female } \\
{[30,32,36,59,63] \text {, Being male [21, 50] }} \\
\text { Socio-economic: Average monthly working days } \\
\text { >24 [55], Unemployment [36, 59], Being main } \\
\text { income earner [51], Low economic status } \\
{[36,61]}\end{array}$ & $\begin{array}{l}\text { Socio-demographic: } \\
\text { Older age }[24,60], \text { Long distance to nearest } \\
\text { HF }[24,25,44], \text { Being female }[19,60,63,68] \text {, } \\
\text { Male sex }[24,27,48,50] \\
\text { Socio-economic: } \\
\text { Low income [43], Unemployment [44], } \\
\text { Labor migration [44] }\end{array}$ & $\begin{array}{l}\text { Socio-demographic: } \\
\text { Being female [19,60, 63, 68],Being male } \\
{[24,27,48,50], \text { Being housewife [19], Higher }} \\
\text { family size [27], Poor literacy [27],Urban } \\
\text { residence [24, 60],Long distance to nearest } \\
\text { HF [24, 25, 44], Older age [24, 60], General } \\
\text { caste [48] }\end{array}$ \\
\hline $\begin{array}{l}\text { Behavioral: } \\
\text { Evil/bad luck perception [29], Knowledge of } \\
\text { coughing }>3 \text { wks as PTB symptom [58], Poor } \\
\text { knowledge of PTB symptoms } \\
{[25,37,48,49,57,59,61] \text {, Perceived social }} \\
\text { stigma [31, 51], Perceived inability to pay for } \\
\text { care [23], Perception that PTB is common } \\
{[21,36] \text {, Belief of PTB is associated with HIV }} \\
{[59,61,64] \text {, Perceiving symptoms as non-serious }} \\
{[22,43] \text {, Belief of PTB is curable }[21,64]}\end{array}$ & $\begin{array}{l}\text { Clinical: } \\
\text { Good functional status [35], No cough [56], } \\
\text { Unusual symptoms other than common ones } \\
\text { [53], Normal chest X-ray [56], Presence of } \\
\text { fever [54], Fibrotic changes on chest x-ray } \odot \\
\text { [52], Smear negativity [28, 37, 53,54,58] }\end{array}$ & $\begin{array}{l}\text { Behavioral: } \\
\text { Perceived stigma [25, 27], Sanitation as } \\
\text { perceived cause [19],1st visit to informal } \\
\text { provider (traditional, religious [24, 25], } \\
\text { Self-medication [44], Smoking [45] }\end{array}$ \\
\hline $\begin{array}{l}\text { Initial Care seeking: } \\
\text { 1st visit at informal provider (traditional, religious) } \\
{[25,29,31,35,37,58] \text {, Self-medication }} \\
{[31,32,44,51,52,62,63] \text {, }} \\
\text { Alcoholism }[44], \text { smoking /tobacco use }[47,63]\end{array}$ & \multirow{2}{*}{$\begin{array}{l}\text { Initial Care seeking: } \\
1 \text { st visit to private facilities (clinics, drug } \\
\text { vendors) [29-31, 35, 44, 50, 58], 1st visit to } \\
\text { informal provider (traditional, religious) [23, 24], } \\
\text { 1st visit to lower level HF [30, 32, 46, 49], } \\
\text { Contact with more than two health } \\
\text { providers [35] }\end{array}$} & $\begin{array}{l}\text { Initial Care seeking: Prior antibiotics } \\
\text { medication, 1st visit to private facility } \\
{[44,50,60] \text {, Multi-facility visit }[25]}\end{array}$ \\
\hline $\begin{array}{l}\text { Clinical: Smear positivity }[29,47], \text { HIV positivity } \\
\text { [44], Being new case }[58] \text {, Chronic/persistent } \\
\text { cough }[44,56,63] \text {, Pulmonary co morbidity } \\
{[37,63] \text {, Mild severity of illness [35], MTB lineage }} \\
7[66], \text { Hemoptysis }{ }^{\oplus}[55,62,63] \text {, Chest pain }{ }^{\oplus}[61] \text {, } \\
\text { Multiple symptoms }^{\oplus}[63]\end{array}$ & & $\begin{array}{l}\text { Clinical: } \\
\text { Chronic cough }[19,44,63] \text {, Only chest pain } \\
\text { [19], } \\
\text { Immunosuppressive therapy (62) }\end{array}$ \\
\hline
\end{tabular}




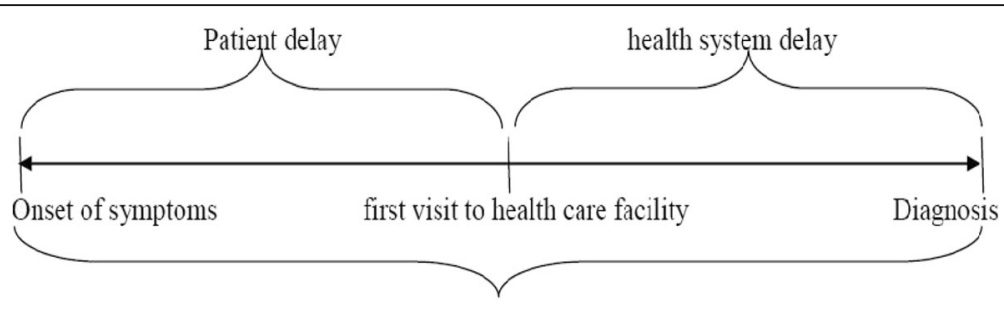

Total Delay

Fig. 1 Illustration of patient, health system and total delay

\section{Patient delay}

The time interval between the onsets of patient recognized PTB symptom(s) recognize and the patient's first consultation to a healthcare provider.

\section{Health system delay}

The time interval between the patient's first consultation with a health care provider and the date of diagnosis.

\section{Diagnosis/Total delay}

The time interval between the onset of PTB symptom(s) and the date of diagnosis. Alternatively, the sum of patient delay and health system delay (Fig. 1).

\section{Data analysis \\ Systematic review}

The data organized on excel spreadsheet were exported to SPSS version 21 for analysis. The median delay (in days) was summarized using median, box plots, inter quartile ranges (25th and 75th percentile), and 95\% confidence interval and ranges. Since the distribution of median delays was skewed, the pooled median delay was taken rather than the mean to compare delays between Sub-Saharan Africa and other LMICs. The median differences were estimated using the non-parametric Mann-Whitney test which was used to test the statistical difference of pooled median delays between Sub-Saharan Africa and other LMICs. In addition, the 95\% confidence interval was calculated using bootstrap method.

\section{Meta-analysis}

The data for each of the six predictor variables were entered into the Comprehensive Meta-analysis software version 2 . The effect size measurement computed were odds ratio (pooled and individual) and prevalence of patient delay at 30 days cutoff point. Forest plots were drawn to visualize effect size (odds ratio with 95\%CI). Both fixed and random effect models were used for pooled analysis based on the heterogeneity level of studies included. Heterogeneity was evaluated using Cochrane $\mathrm{Q}$ and $\mathrm{I}^{2}$ tests as well as $\mathrm{Q} / \mathrm{df}$ (degree of freedom) ratio. Cochrane $\mathrm{Q}$ test $(p=0.1), \mathrm{Q} / \mathrm{df}=1$ and $\mathrm{I}^{2}$ $=50 \%$ were considered as cutoff points to mark heterogeneity and to select the effect model for combined analysis.

As initial test of pooled analysis, we used fixed effect model to combine individual effect sizes. If there was no heterogeneity observed during initial test using fixed effect model (i.e. $P>0.1$ and $\mathrm{I}^{2} \leq 50 \%$ and $\mathrm{Q} / \mathrm{df} \leq 1$ or $p \leq$ 0.1 but $\mathrm{I}^{2} \leq 50 \%$ ), we used fixed model as final model to estimate combined effect sizes. However, if there was significant heterogeneity observed (i.e. $\mathrm{p} \leq 0.1$ and $\mathrm{I}^{2}>$ $50 \%$, or $p>0.1$ but $\mathrm{Q} / \mathrm{df}>1$ ), we used random effect model. The sources of heterogeneity were assessed by subgroup analysis based on clinical heterogeneity of the studies mainly using smear status of participants. Funnel plot and Egger's regression test were used for checking graphic and statistical publication biases, respectively. Sensitivity test was done to check the effect of each study on combined effect size.

\section{Results}

Description of selected studies

A total of 40 eligible studies were retrieved for systematic review; 19 (47.5\%) from sub-Saharan Africa, 20 (50\%) from other LMICs, and 1 (2.5\%) study involved three countries (Bangladesh, India and Malawi). Among these, 14 studies were found to be eligible for metaanalysis, two with 15 days and 12 with 30 days cutoff points to categorize patient delay (Fig. 2). The numbers of studies which measured patient, health system and total median delays were 35, 27 and 30 respectively (Tables 3 and 4). All but one study used cross-sectional study design with either one time or prospective participant recruitment strategy.

There was certain level of variation on categorization of delays across reviewed studies. Majority of the studies categorized time in diagnosis into 'delayed' and 'not delayed' using cutoff point. However, there was no uniform cutoff point across all studies. Some studies used the median of their finding, and others used 2 weeks (15 days), 3 weeks (21 days), 1 month (30 days). With no justification, one study used 6 and 12 weeks as cutoff 


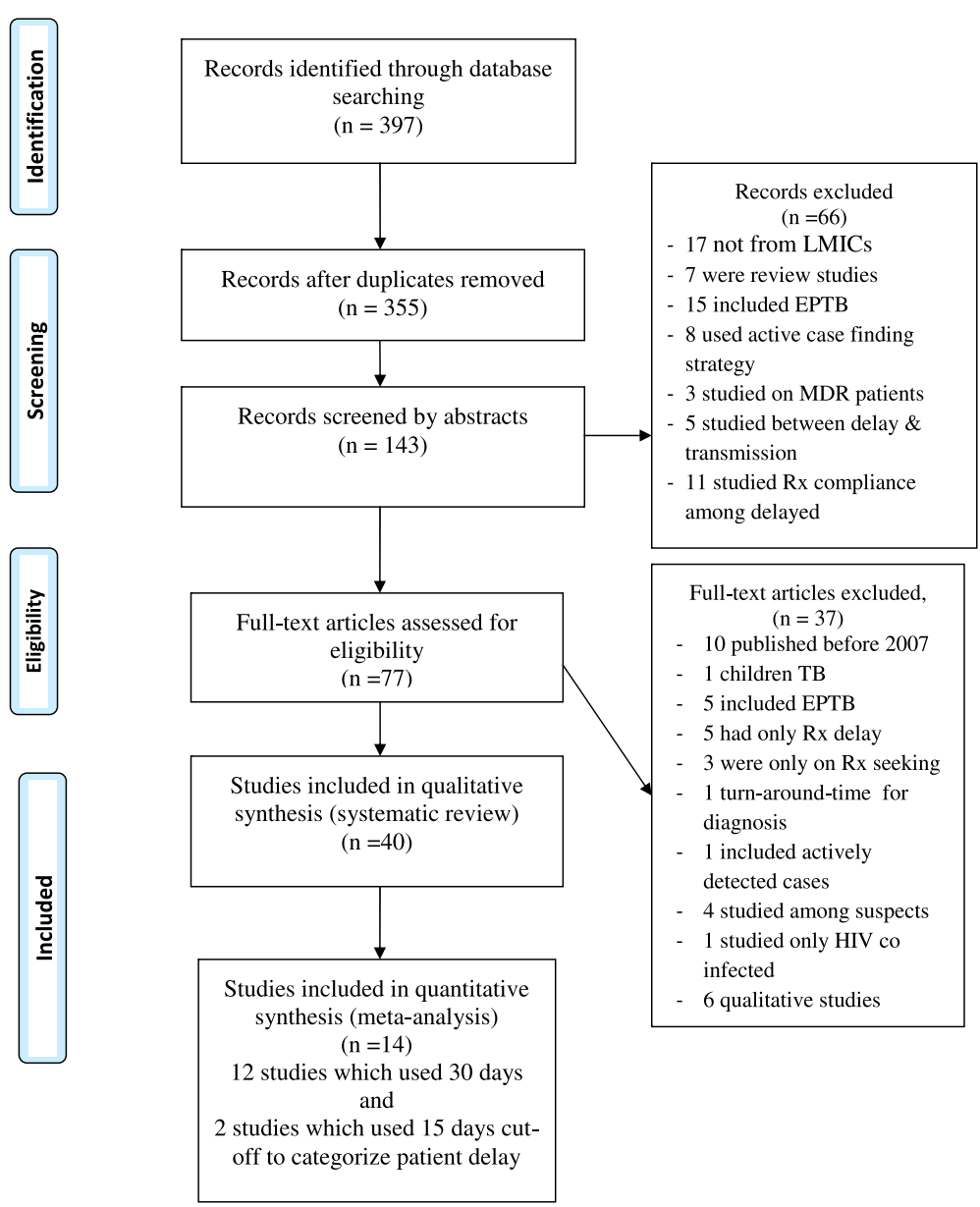

Fig. 2 PRISMA flow diagram for article selection and screening

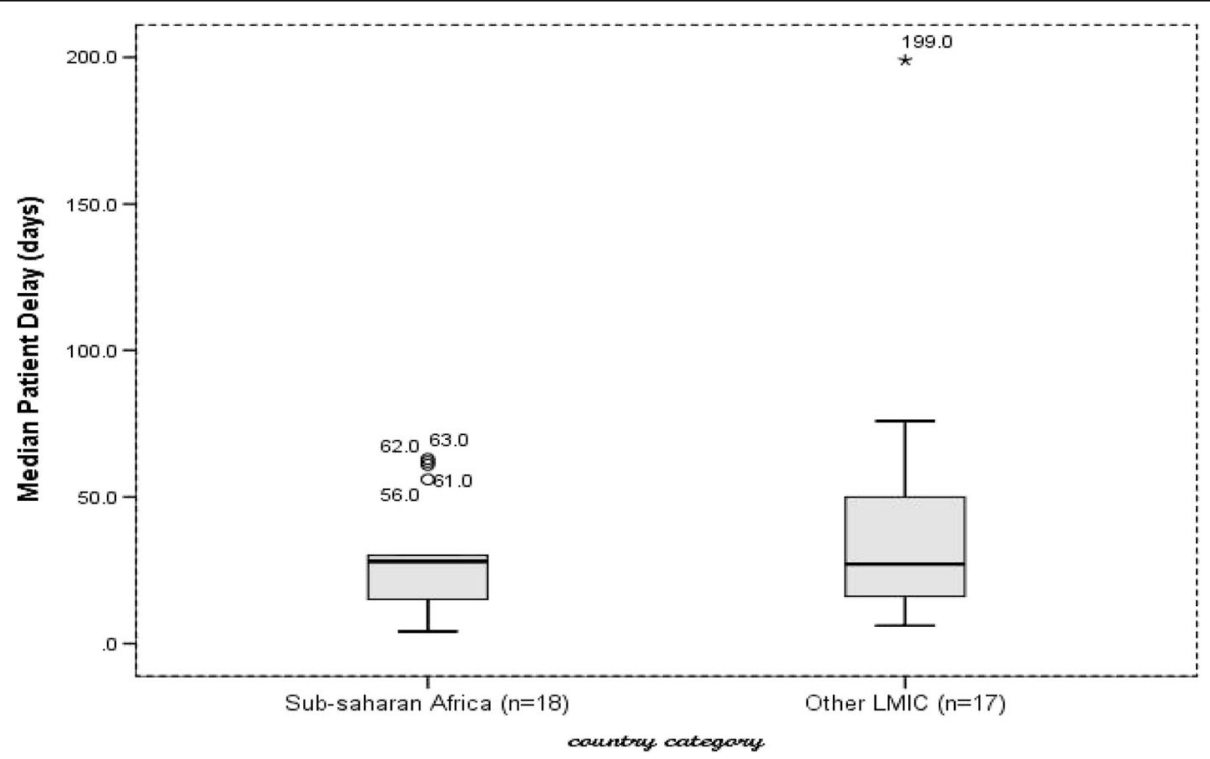

Fig. 3 median patient delay in Sub-Saharan Africa and other Low- and Middle-Income countries, 2007 to 2015 


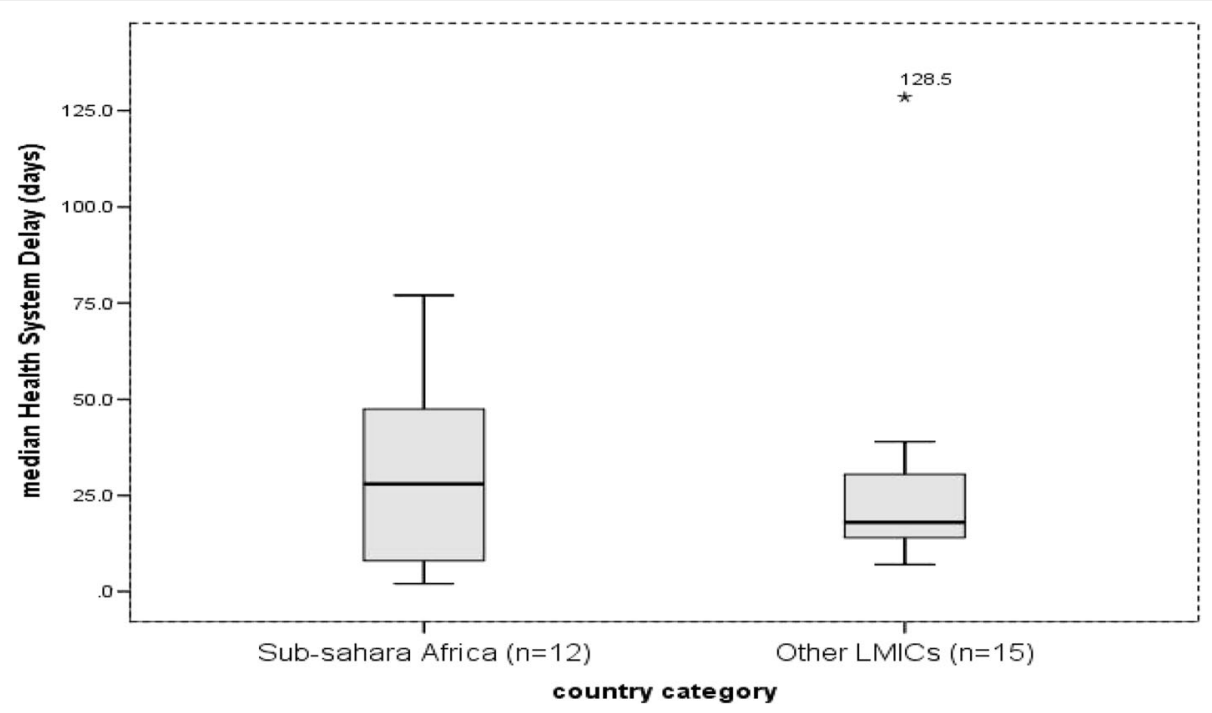

Fig. 4 median health system delay in Sub-Saharan Africa and other Low- and Middle-Income countries, 2007 to 2015

point to determine patient and total delays, respectively [30]. A few studies considered delay as continuous variable, and computed linear regression, ANOVA and Mann-Whitney test.

\section{Diagnosis delay overview}

The overall median delay in LMICs ranged from 4 to 199 days (25th \& 75th percentile $=15 \& 50$ ) for patient delay, 2 to 128.5 days ( 25 th $\& 75$ th percentile $=12 \& 34$ ) for health system delay, and 30 to 366.5 days (25th\& 75 th percentile $=44 \& 78.8$ ) for total delay. All of the highest median patient (199), health system (128.5) and total (366.5) delays were reported from Afghanistan [31]. The mean patient delay (35.5 days, $95 \% \mathrm{CI}=24.4-55.4$ ) was similar to mean health system delay (28.7 days, 95\%CI $=19.7-45.8), p>0.05$.

\section{Patient delay}

The median patient delay in Sub-Saharan Africa varied from 4 days in Sudan to 63 days in Ethiopia, and median of the reported median delays was 28 days $(95 \% \mathrm{CI}=$ 18.9-41.7). In other LMICs, it varied from 6 in India to 199 days in Afghanistan, and median of the reported median delays was 27 days $(95 \% \mathrm{CI}=16.5-55.4)$. There

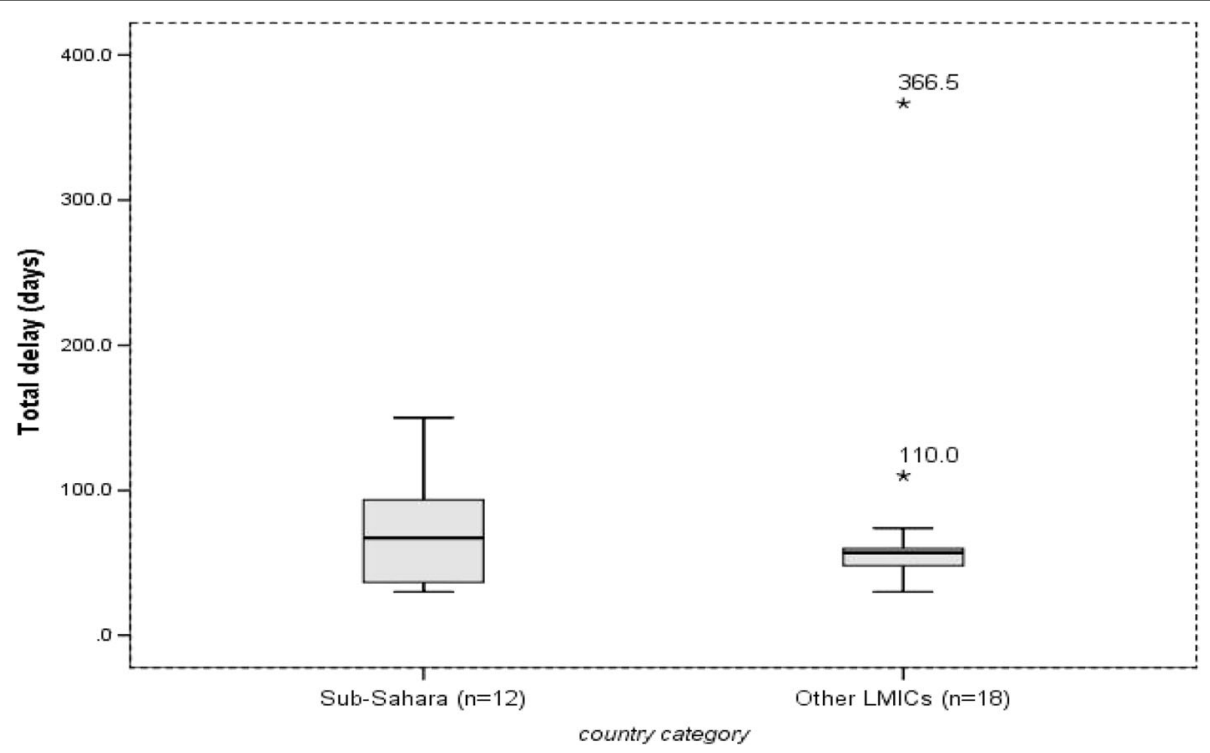

Fig. 5 median total delay in Sub-Saharan Africa and other Low- and Middle-Income countries, 2007 to 2015 


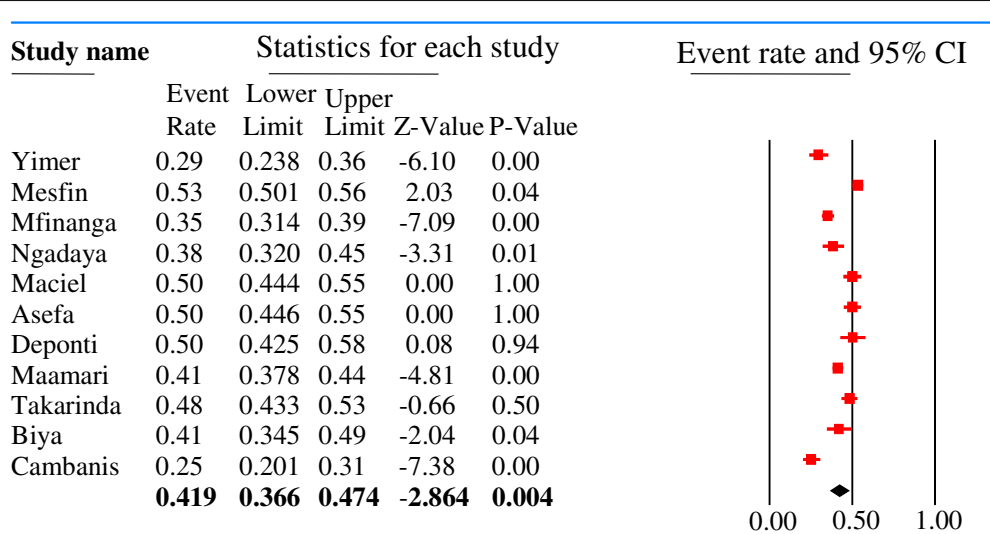

Fig. 6 Forest plot showing the pooled proportion of patient delayed above 30 days to seek formal medical care

was no statistically significant difference observed between the two groups, $p=0.49$ (Fig. 3).

Our review identified a wide range of factors affecting patient delay that were related to individual, health system and clinical characteristics. Some of the individual factorswere poor literacy, first care seeking from informal providers, self-medication, sex (mostly female), wrong perceptions and rural residence among others. The clinical factors were being a new case, mild severity of illness, chronic/persistent cough and pulmonary co-morbidity. On the contrary, the presences of hemoptysis, chest pain and multiple symptoms reduced patient delay (Table 5).

\section{Health system delay}

The median health system delay in Sub-Saharan countries ranged from the lowest of 2 days in Zimbabwe to 77 days in Uganda and the median of reported median delays was 28 days (95\%CI: 14-35.9). In other LMICs, it varied from 7 days in Vietnam and Uzbekistan to 128.5 days in Afghanistan, and the median of reported median delays was 18 days (95\%CI: $14-30)$. However, no median difference between the two groups was observed, $p=0.35$ (Fig. 4).

Individual factors related to health systems delay were poor literacy, sex (mainly being female), being unemployed and labor migrant while good functional status, absence of cough, presence of unusual symptoms, normal chest X-ray, and smear negativity results were among the clinical factors. First care seeking at private or lower-level health facility was also identified as determinant of health system delay (Table 5).

\section{Total delay}

The median total delay in Sub-Saharan countries ranged from the lowest of 30 days in Zimbabwe to 150 days in Mozambique, and the median of reported median total delays was 67 days (95\%CI: 37-90). In other LMICs, it varied from the lowest median delay of 30 days in Vietnam to 366.5 days in Afghanistan, and the median of reported median total delays was 57 days (95\%CI: 49-66.8). There was no median difference between the two groups, $p=$ 0.31 . Outlier median total delays of 110 and 366.5 were reported from Brazil and Afghanistan, respectively (Fig. 5).

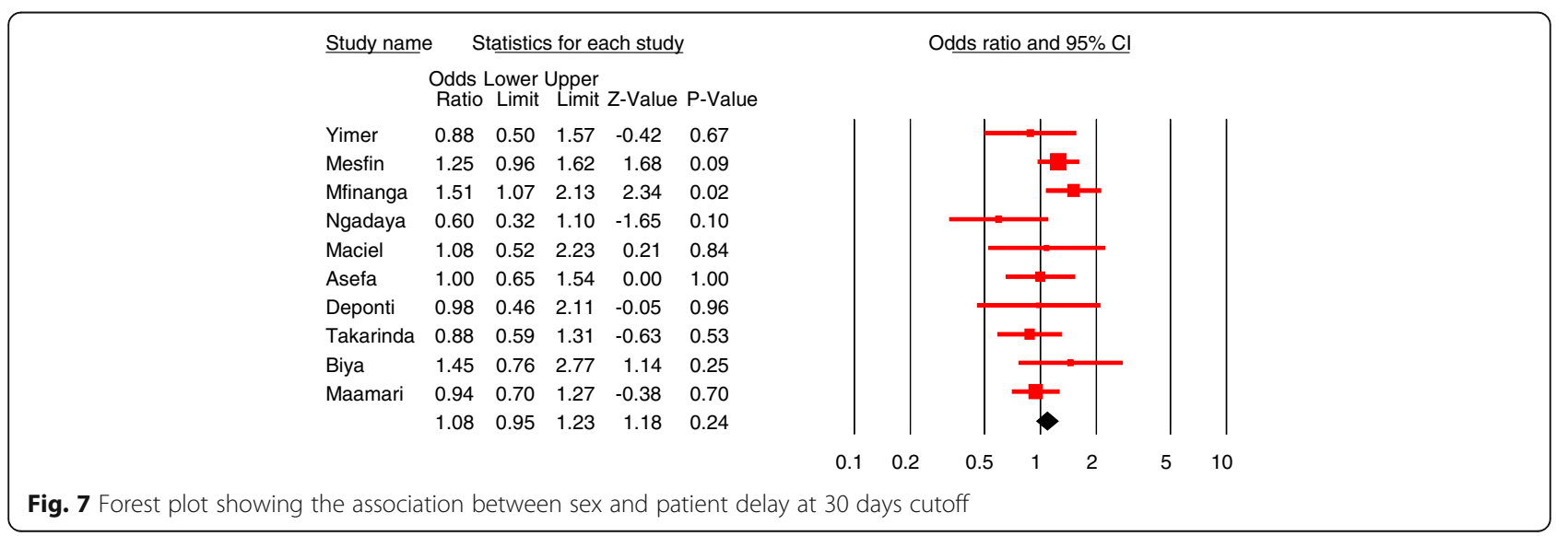




\begin{tabular}{lrrrrr} 
Study name & \multicolumn{5}{c}{ Statistics for each study } \\
& $\begin{array}{r}\text { Odds } \\
\text { Ratio }\end{array}$ & $\begin{array}{r}\text { Lower } \\
\text { Limit }\end{array}$ & $\begin{aligned} \text { Upper } \\
\text { Limit }\end{aligned}$ & Z-Value & P-Value \\
Hussen 2012 & 2.306 & 0.693 & 7.675 & 1.362 & 0.173 \\
Ngangro2012 & 1.131 & 0.687 & 1.860 & 0.484 & 0.628 \\
& 1.255 & 0.792 & 1.988 & 0.968 & 0.333
\end{tabular}

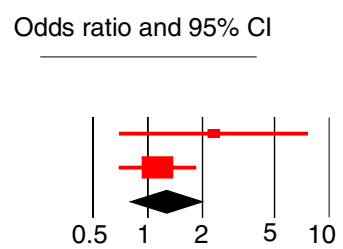

Fig. 8 Forest plot showing the association between sex and patient delay at 15 days cutoff

The determinants of total delay were a mix of factors affecting patient or health system delay (Table 5).

\section{Summary of findings from meta-analysis}

The combined analysis of 12 studies indicated that $42 \%$ $(95 \% \mathrm{CI}=37-47 \%)$ of PTB patients delayed a month or more without seeking formal medical care $(\mathrm{Q}=123, p<$ $\left.0.1, \mathrm{df}=10, \mathrm{I}^{2}=91 \%\right)$. Significant heterogeneity existed following subgroup analysis by smear type (any type and smear positive) (Fig. 6).

Pooled effect sizes were estimated to determine the independent effect of sex, residence, educational status, first care seeking from informal provider and HIV status on patient delay, and 11, 4, 9, 4 and 3 studies (with 30 days cutoff point) were analyzed, respectively. In addition, 2 studies (with 15 days cutoff) were also pooled.

The majority of studies identified females were more likely to delay but the quantitative summary indicated no statistically significant difference in patient delay between female and male PTB patients at 30 days [pooled $\mathrm{OR}=1.08,95 \% \mathrm{CI}=0.95-1.23, p=0.24] \quad$ (Fig. 7) and 15 days cutoff points [pooled OR $=1.26,95 \% \mathrm{CI}=0.79$ 1.99] (Fig. 8). No heterogeneity was observed at both cutoff points (Fig. 9). Similarly, there was no statistically significant difference in patient delay between rural and urban PTB patients at 30 days cutoff [pooled $\mathrm{OR}=1.06$, $95 \% \mathrm{CI}=0.66-1.71, p=0.81$ ] (Fig. 10) but observed at 15 days cutoff [pooled $\mathrm{OR}=2.4,95 \% \mathrm{CI}=1.4-4.1, p=$ 0.002] (Fig. 11).

Literacy had significant association [pooled OR $=1.5$, $95 \% \mathrm{CI}=1.1-1.9, p=0.01]$, and the odds of patient delay was greater among illiterate PTB patients as compared to those who had formal educition. Significant heterogeneity was observed $\left[\mathrm{Q}=14.3, \mathrm{p}=0.01, \mathrm{df}=5, \mathrm{I}^{2}=65 \%\right]$ (Fig. 12). First care seeking from informal providers had statistically significant association with patient delay at 30 days cutoff [pooled $\mathrm{OR}=3,95 \% \mathrm{CI}=2.3-3.9, p<$ 0.05]; PTB patients who sought first care at informal providers were 3 times more to delay by a month or more to seek care compared to their counterparts. No heterogeneity was observed $\left[\mathrm{Q}=1.7, p=0.64, \mathrm{df}=3, \mathrm{I}^{2}\right.$ $=0 \%$ ] and Egger's regression test, $p=0.23$ (Fig. 13). The patient delay had no statistically significant association with HIV [pooled OR $=0.98,95 \% \mathrm{CI}=0.79-1.21, p=$ 0.84] (Fig. 14).

\section{Discussion}

Our systematic review and meta-analysis indicated that the extent of delay in diagnosis of PTB remains a serious

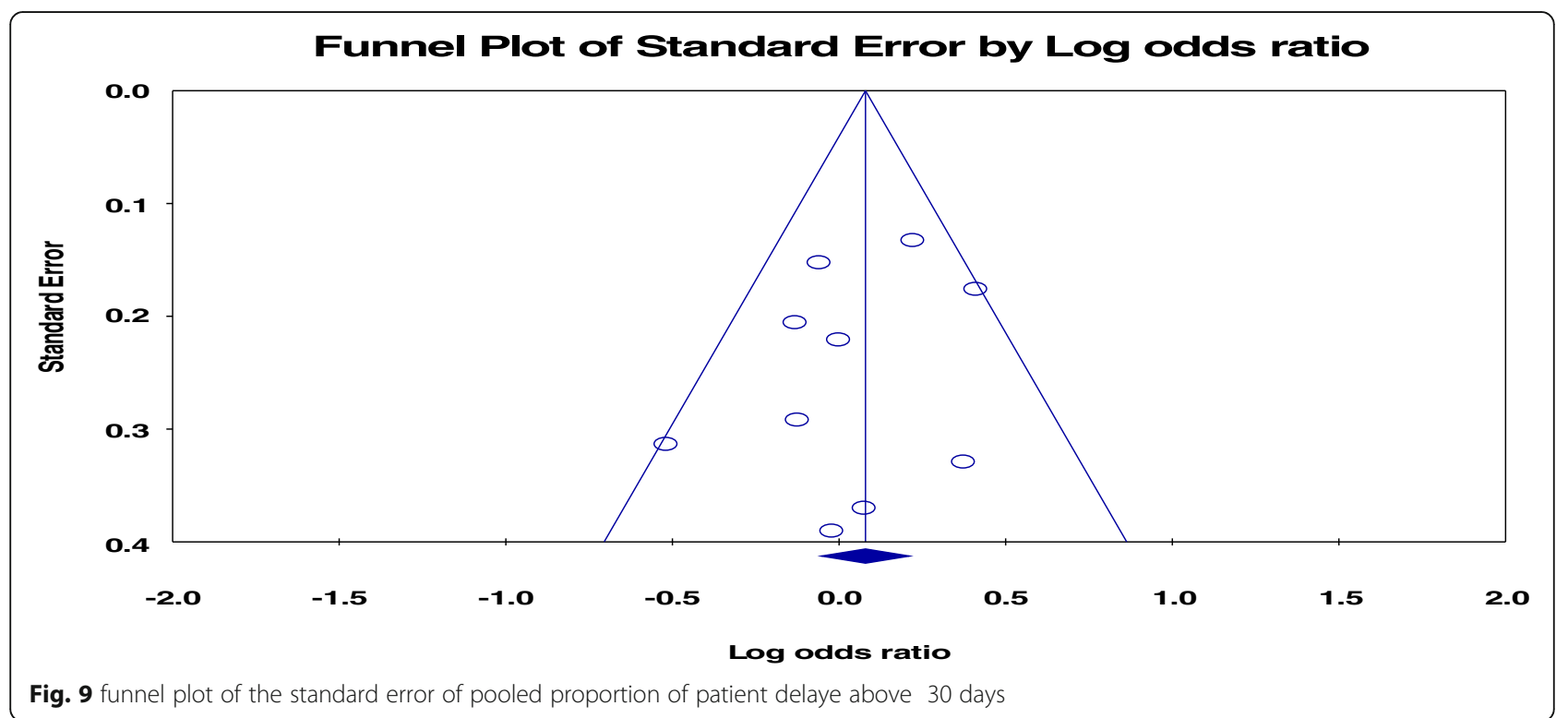




\section{Study name $\quad$ Statistics for each study $\quad$ Odds ratio and 95\% CI}

\begin{tabular}{|c|c|c|c|c|}
\hline & $\begin{array}{l}\text { Odds } \\
\text { Ratio }\end{array}$ & $\begin{array}{l}\text { Lower Upper } \\
\text { LimitLimit Z-Value }\end{array}$ & P-Value & $\begin{array}{l}\text { Relative } \\
\text { Weight }\end{array}$ \\
\hline Mesfin & 1.89 & $1.462 .46 \quad 4.78$ & 0.00 & 29.03 \\
\hline Cambanis & 0.67 & $\begin{array}{lll}0.31 & 1.45 & -1.02\end{array}$ & 0.31 & 17.46 \\
\hline Maamari & 1.07 & $\begin{array}{lll}0.80 & 1.43 & 0.46\end{array}$ & 0.65 & 28.46 \\
\hline Takarinda & 0.74 & $\begin{array}{lll}0.48 & 1.15 & -1.35\end{array}$ & 0.18 & 25.06 \\
\hline & 1.06 & $\begin{array}{lll}0.66 & 1.71 & 0.24\end{array}$ & 0.81 & \\
\hline
\end{tabular}

Fig. 10 Forest plot showing the association between residence and patient delay at 30 days cutoffs

challenge for TB control programs in low- and middleincome countries. Half of the studies in this review reported a median diagnosis delay higher than 2 months, both patient and health system delays made comparable contributions.

This review shows the extent of delays in diagnosis of PTB continued to be as bad as it was a decade ago [6]. Our review showed no significant difference in patient, health system and total delays of PTB cases between Sub-Saharan Africa and other LMICs. Delays have been a common problem to all LMICs which harbor a large share of global TB burden. The minimum median total delay in diagnosis was 30 days in this review [30, 32] which has been indicated as a turning point at which a significant increase in risk for TB transmission occurs [33]. WHO recommends diagnosis within 2 to 3 weeks of symptom initiation [20] though the acceptable time delay is not known. Considering the WHO cutoff point recommendations, this review has, therefore, indicated unacceptable level of delay occurring in LMICs, and actual delays may even be worse than reported here as patients are likely to recall the date when the illness gets severe but not exact date of illness onset.

In this review, the qualitative and quantitative summary of studies indicated the observed patient, and health system delays in LMICs were attributed by a set of individual and health system related factors. The individual factors are related to characteristics of the patients and skill of healthcare providers that influence the health seeking behavior of patients, and suspicion and detection of the disease by healthcare providers. These include demographic, socio-economic, knowledge, beliefs, perceived barriers, behaviors, clinical features and provider skills (the details stated below). The health system factors comprise factors which drive within the health system, and hinder access to health facilities and limit availability of diagnosis services. These include limited access of health facilities near to villages, lack of TB diagnosis services in easily accessible health facilities such as private facilities, drug vendors and lower level facilities (e.g. health posts), high cost of some diagnostics (pathology and X-ray), and existence of informal healers (traditional and religious) providing unlimited therapeutic services.

Even though higher number of studies (five) reported that female patients were more likely to wait longer periods without medical consultation, the pooled analysis indicated that sex was not the independent determinant of patient delay $(p=0.24)$. This may be due to gender based social influence in health decision making that might vary across cultures and countries. Similarly, our pooled analysis showed residence was not the independent determinant of patient delay, but three studies in Ethiopia [29, 34, 35] reported rural residence and three other studies from Iran, Nigeria and Sudan [24, 36, 37] reported urban residence as independent determinants

$$
\begin{aligned}
& \text { Study name Statistics for each study Odds ratio and } 95 \% \text { CI } \\
& \text { Odds Lower Upper } \\
& \text { Ratio Limit Limit Z-Value P-Value } \\
& \text { Hussen } 2012 \quad 4.29 \quad 1.41 \quad 13.0 \quad 2.57 \quad 0.01 \\
& \text { Ngangro } 2012 \quad 1.97 \quad 1.05 \quad 3.7 \quad 2.10 \quad 0.04 \\
& \begin{array}{lllll}
2.38 & 1.38 & 4.12 & 3.10 & 0.002
\end{array}
\end{aligned}
$$

Fig. 11 Forest plot showing the association between residence and patient delay at 15 days cutoffs 


\begin{tabular}{|c|c|c|c|c|c|c|c|}
\hline \multicolumn{2}{|c|}{ Study name } & \multicolumn{4}{|c|}{ Statistics for each study } & Odds ratio and $95 \% \mathrm{CI}$ & \multirow[b]{2}{*}{$\begin{array}{l}\text { Relative } \\
\text { Weight }\end{array}$} \\
\hline & $\begin{array}{l}\text { Odds } \\
\text { Ratio }\end{array}$ & $\begin{array}{l}\text { Lower } \\
\text { Limit }\end{array}$ & $\begin{array}{l}\text { Upper } \\
\text { Limit }\end{array}$ & Z-Value & P-Value & & \\
\hline Yimer & 1.63 & 0.92 & 2.88 & 1.68 & 0.09 & & 13.49 \\
\hline Mesfin & 1.94 & 1.49 & 2.53 & 4.94 & 0.00 & & 22.65 \\
\hline Mfinanga & 1.67 & 1.14 & 2.45 & 2.65 & 0.01 & & 18.81 \\
\hline Ngadaya & 0.80 & 0.45 & 1.41 & -0.77 & 0.44 & & 13.54 \\
\hline Maamari & 1.07 & 0.79 & 1.45 & 0.45 & 0.65 & - & 21.37 \\
\hline Maciel & 2.08 & 1.00 & 4.31 & 1.97 & 0.05 & & 10.14 \\
\hline & 1.45 & 1.08 & 1.94 & 2.50 & 0.01 & & \\
\hline
\end{tabular}

Fig. 12 Forest plot showing the association between educational status and patient delay at 30 days cutoff

of patient delay. This may be owing to the health system of the respective countries. For instance, most patients in rural areas of Ethiopia have primary access to the health post (first level of the health system) where there are no TB diagnostic services [38] and patients might have to walk for some hours to access hospitals or health centers. This is supported by considerable number of studies in our review that indicated patients who travel long distance to access healthcare services experienced longer patient delays in both settings.

Our pooled analysis showed that illiterate patients were more likely to delay in seeking care compared to those patients who had formal education (pooled $\mathrm{OR}=$ 1.5 ; $95 \% \mathrm{CI}=1.1-1.9$ ). Illiteracy may limit patients' access to written health education and communication materials that are commonly utilized to increase public awareness about the disease [5]. Our review also found poor knowledge of PTB sign and symptoms, cause and treatment lengthened patient delay in LMICs. Patients who believed the cause of TB is evil/bad luck, perceived the symptoms are common and not dangerous, feared social stigmatization/embarrassment, and associated PTB with HIV sought medical consultation after long suffer from the disease. This is because such limited knowledge and perceived barriers direct patients to hide their illness, self-medicate and practice traditional healing [39]. In addition, poor understanding of the disease in the community results in being discriminated by peers, friends, neighbors and so on [40].
Our meta-analysis identified first care seeking from informal providers as a key determinant of patient delay (pooled OR $=3 ; 95 \% \mathrm{CI}=2.3-3.9$ ). Similarly, another review identified patients consulting traditional healers first have experienced patient delay usually in rural residents of Sub-Saharan Africa [11]. This is because patients who have poor knowledge of PTB cause and/or believe PTB is acquired from evil curse deemed trust on treatment by traditional healers or religious leaders to be freed from evil spirits [41]. This implies traditional/religious healers are still preferred destinations for substantial number TB patients. Therefore, engaging them could help to identify presumptive cases early, establish referral link to TB care centers, avoid traditional therapy, and to target community misperceptions and wrong beliefs that hassled healthcare seeking.

Patients who had chronic cough, pulmonary comorbidity and mild severity of illness delayed seeking care. This may be because patients with such type of symptoms may suspect other common respiratory syndromes that are not considered serious. However, the presence of hemoptysis, chest pain and multiple symptoms reduced the possibility of patient delay. Beyond delaying care seeking, clinical presentations affected the time of diagnosis once patients consulted health care providers. Patients presented with good functional status, no cough and had unusual symptoms obtained delayed diagnosis from the health system. These appearances may hinder PTB suspicion by heath care providers or they may fail to suspect

\begin{tabular}{|c|c|c|c|c|c|}
\hline \multicolumn{2}{|c|}{ Study name } & \multicolumn{4}{|c|}{ Statistics for each study } \\
\hline & $\begin{array}{l}\text { Odds } \\
\text { Ratio }\end{array}$ & $\begin{array}{l}\text { Lower } \\
\text { Limit }\end{array}$ & $\begin{aligned} \text { Upper } \\
\text { Limit }\end{aligned}$ & & \\
\hline Mesfin & 3.235 & 2.354 & 4.447 & 7.234 & 0.000 \\
\hline Ngad & 3.095 & 1.282 & 7.472 & 2.513 & 0.012 \\
\hline Caml & 3.040 & 1.422 & 6.500 & 2.868 & 0.004 \\
\hline Takarinda & 1.921 & 0.937 & 3.935 & 1.784 & 0.074 \\
\hline & 2.988 & 2.305 & 3.874 & 8.267 & 0.000 \\
\hline
\end{tabular}

Odds ratio and $95 \% \mathrm{CI}$

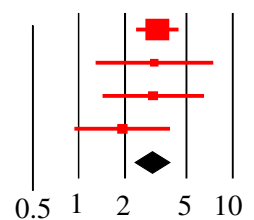

Fig. 13 forest plot showing the association between 1st care seeking from informal provider and patient delay of PTB patients (30 days cutoff) 


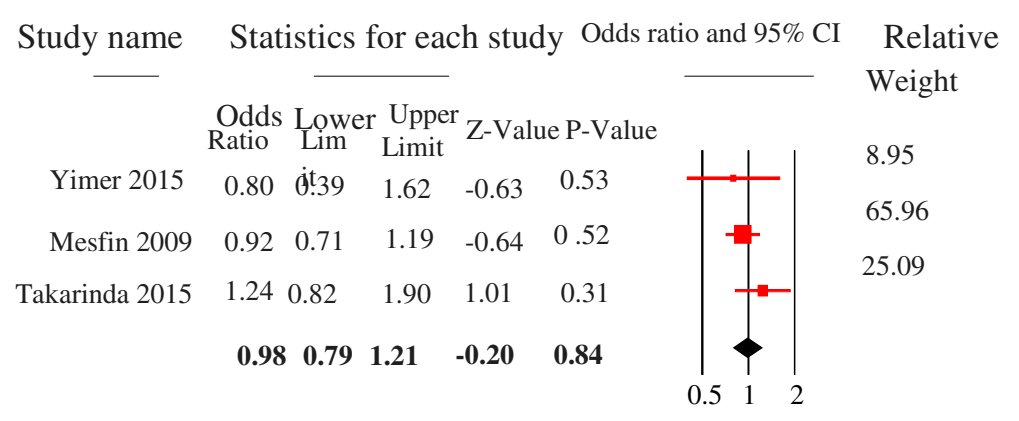

Fig. 14 Forest plot showing the association between HIV status and patient delay at 30 days cutoff

PTB as of poor skill in identifying rare symptoms. Normal chest X-ray and smear negative results at initial diagnosis have also delayed PTB diagnosis. This may be related to the poor skill of healthcare providers in detecting the disease or poor sensitivity of diagnostic methods to detect cases at early stage [42].

Our review indicated that considerable number PTB patients in LMICs sought initial care from private clinics, drug vendors and lower level public health facilities where TB diagnosis services are unavailable [30]. So, if these health providers are engaged in TB services, they will contribute greatly in identification of presumptive cases and refer to nearby higher health facilities in their setting. Patients who sought care from multiple providers are likely to experience health system delay [35]. In addition, unemployment, labor migration and low income were also reported as factors of health system delay. This might be due to the high costs for pathological and $\mathrm{x}$-ray diagnosis which are not free of charge globally unlike the rest of $\mathrm{TB}$ services [43].

Despite these findings and scientific arguments, it appears to have some methodological limitations that arose from either individual studies or the review process. Only English articles were reviewed. There could be many articles written in other languages that might be different with respect to size and quality. All included studies except one were cross-sectional. Therefore, methodological bias and confounding which are common in cross-sectional studies might have been introduced. Furthermore, there was lack of detailed information and inconsistent reporting among retrieved studies. Some studies computed separate median patient delay (stratified analysis), few reported $p$-value only [44], no clear cutoff point to categorize delay, and the variability of predictor variables across the studies. This limited the number of studies and predictor variables considered in the meta-analysis that could affect the power of the pooled analysis.

\section{Conclusion}

This systematic review and meta-analysis confirms delays in diagnosis of PTB have remained higher similar to the preceding periods. Both patient and health system delays have contributed for observed delay all over the high burden low- and middle- income countries. This implies that the existing strategies and efforts under implementation did not appear to improve the desired early PTB case presentation, detection and prompt treatment initiation in low- and middle- income countries.

Multiple patient, provider and health system related factors seemed to contribute for the observed high diagnosis delays. The pooled analysis confirmed poor literacy and preference to seek care from informal healers significantly associated with patient delay. Substantial numbers of PTB patients still sought initial TB care from private healthcare facilities, traditional/religious healers and low level/community health workers. Hence, systematic engagement of these parties would potentially improve case finding strategies. If they are engaged in presumptive case identification and active referral network with TB care facilities established, early care seeking and detection can substantially be improved. Continuous community awareness activities should also be strengthened.

\section{Abbreviations}

$\mathrm{Cl}$ : Confidence interval; HIV: Human immuno-deficiency virus;

IQR: Inter-Quartile Range; LMICS: Low- and Middle-Income Countries; NTP: National tuberculosis control programs; OR: Odds Ratio;

PRISMA: Preferred reporting items for systematic reviews and meta-analyses; PTB: Pulmonary Tuberculosis; TB: Tuberculosis; WHO: World Health Organization

\section{Acknowledgements \\ We are very grateful to the authors of the articles included in this review. Our heartfelt gratitude extends to Haramaya University for facilitating the review process. We are very thankful to PhD fellows and faculty at the School of Public Health, Haramaya University, for their constructive comments. Our especial gratitude goes to Manendante Mulugeta (PhD in TEFL) for his language edition.}

\section{Availability of data and materials}

The datasets which illustrate the findings of this study and our conclusions relied on are annexed tables at the end of the manuscript. The data could be freely available for anyone interested.

\section{Authors' contributions}

FG initiated the conception of this review, conducted literature search, assessed the studies, carried out the systematic review and meta-analysis, 
and wrote the first draft of the manuscript. MD enriched the conception, revised and approved the final manuscript. NA directed the design, assisted and supervised the review starting from the scratch and commented on the earlier drafts of the manuscripts. BM directed the design, supervised the review and commented on the earlier drafts of the manuscripts. AW commented on the final draft and revised the manuscript. All the authors read and approved the final version of the manuscript to be sent for publication. The sequence of authorship depends on their level of contribution to this paper.

\section{Ethics approval and consent to participate}

Not applicable.

\section{Consent for publication}

Not applicable.

\section{Competing interests}

The authors declare that they have no competing interests.

\section{Publisher's Note}

Springer Nature remains neutral with regard to jurisdictional claims in published maps and institutional affiliations.

\section{Author details}

'Department of Public Health, College of Medicine and Health Sciences, Jigjiga University, PO Box $=1020$, Jigjiga, Ethiopia. ${ }^{2}$ Addis Continental Institute of Public Health, Addis Ababa, Ethiopia. ${ }^{3}$ School of Public Health, College of Health and Medical Sciences, Haramaya University, Harar, Ethiopia. ${ }^{4}$ School of Public Health, College of Health Sciences, Addis Ababa University, Addis Ababa, Ethiopia.

Received: 10 August 2017 Accepted: 30 November 2017

Published online: 13 December 2017

\section{References}

1. WHO. Global tuberculosis report 2017. Geneva: World Health Organization; 2017. Available at http://apps.who.int/iris.

2. WHO. The global plan to stop TB 2011-2015: Transforming the fight towards elimination of tuberculosis. World Health Organization; 2010.

3. WHO. Systematic screening for active tuberculosis: principles and recommendations. Geneva: World Health Organization; 2013.

4. WHO. Treatment of tuberculosis: guidelines. Geneva: World Health Organization; 2010

5. Li Y, Ehiri J, Tang S, Li D, Bian Y, Lin H, et al. Factors associated with patient, and diagnostic delays in Chinese TB patients: a systematic review and meta-analysis. BMC Med. 2013:11(1):156.

6. Sreeramareddy CT, Panduru KV, Menten J, Van den Ende J. Time delays in diagnosis of pulmonary tuberculosis: a systematic review of literature. BMC Infect Dis. 2009:9:91.

7. Storla DG, Yimer S, Bjune GA. A systematic review of delay in the diagnosis and treatment of tuberculosis. BMC Public Health. 2008;8:15.

8. Shah NS, Yuen CM, Heo M, Tolman AW, Becerra MC. Yield of contact investigations in households of patients with drug-resistant tuberculosis: systematic review and meta-analysis. Clin Infect Dis. 2014;58(3):381-91.

9. Jia ZCS, Ma Y, Zhang Y, Bai L, Xu W, He X, Zhang P, Zhao J, Christiani DC. Tuberculosis burden in China: a high prevalence of pulmonary tuberculosis in household contacts with and without symptoms. BMC Infect Dis. 2014;14 64.

10. Cheng S, Chen W, Yang Y, Chu P, Liu X, Zhao M, et al. Effect of diagnostic and treatment delay on the risk of tuberculosis transmission in Shenzhen, China: an observational cohort study, 1993-2010. PLoS One. 2013;8(6): e67516.

11. Finnie RK, Khoza LB, van den Borne B, Mabunda T, Abotchie P, Mullen PD. Factors associated with patient and health care system delay in diagnosis and treatment for TB in sub-Saharan African countries with high burdens of TB and HIV. Tropical Med Int Health. 2011:16(4):394-411.

12. $\mathrm{FMOH}$. Guidelines for clinical and Programatic Manageent of TB, leprosy and TB/HIV in Ethiopia. In: TB L, TB/HIV. 5th ed. Addis Ababa: Federal Ministry Of Health of Ethiopia; 2012

13. Fox GJ, Barry SE, Britton WJ, Marks GB. Contact investigation for tuberculosis: a systematic review and meta-analysis. Eur Respir J. 2013;41(1):140-56.
14. Uplekar M, Figueroa-Munoz J, Floyd K, Getahun H, Jaramillo E. The stop TB strategy: building on and enhancing DOTS to meet the TB-related millennium development goals. Geneva: World Health Organization; 2006. WHO/HTM/TB/2006.368.

15. LA Moher D, Tetzlaff J, Altman DG. Preferred reporting items for systematic reviews and meta-analyses: the PRISMA statement. PLoS Med. 2009;6(6): e1000097.

16. Matthews JR, Matthews RW. Successful scientific writing: a step-by-step guide for the biological and medical sciences. New York: Cambridge University Press; 2014. Available at www.cambridge.org/9780521699273.

17. National Collaborating Center for Environmental Health. A Primer for Evaluating the Quality of Studies on Environmental Health: Critical Appraisal of Cross-Sectional Studies. Ottowa: National Collaborating Centre for Environmental Health; 2011.

18. National Heart, Lung, and Blood Institute. "Quality assessment tool for observational cohort and cross-sectional studies". Bethesda: National Institutes of Health, Department of Health and Human Services; 2014

19. Gosoniu GD, Ganapathy S, Kemp J, Auer C, Somma D, Karim F, Weiss MG. Gender and socio-cultural determinants of delay to diagnosis of TB in Bangladesh, India and Malawi. Int J Tuberc Lung Dis. 2008;12(7):848-55.

20. WHO. Early detection of tuberculosis: an overview of approaches, guidelines and tools. Geneva: World Health Organizatiom; 2011. WHO/HTM/STB/PSI/ 2011.21.

21. Ford CM, Bayer AM, Gilman RH, Onifade D, Acosta C, Cabrera L, et al. Factors associated with delayed tuberculosis test-seeking behavior in the Peruvian Amazon. Am J Trop Med Hyg. 2009;81(6):1097-102.

22. Ekinci GH, Karakaya E, Ongel EA, Haciomeroglu O, Yilmaz A. Patient and doctor delays in smear-negative and smear-positive pulmonary tuberculosis patients attending a referral hospital in Istanbul, Turkey. The Scientific World Journal. 2014; Article ID 158186

23. Tamhane A, Ambe G, Vermund SH, Kohler CL, Karande A, Sathiakumar N. Pulmonary tuberculosis in Mumbai, India: factors responsible for patient and treatment delays. Int J Prev Med. 2012;3(8):569-80.

24. Ukwaja KN, Alobu I, Nweke CO, Onyenwe EC. Healthcare-seeking behavior, treatment delays and its determinants among pulmonary tuberculosis patients in rural Nigeria: a cross-sectional study. BMC Health Serv Res. 2013; 13:25

25. Maamari F. Case-finding tuberculosis patients: diagnostic and treatment delays and their determinants. East Mediterr Health J. 2008;14(3)

26. Yimer SA, Norheim G, Namouchi A, Zegeye ED, Kinander W, Tønjum T, et al. Mycobacterium tuberculosis lineage 7 strains are associated with prolonged patient delay in seeking treatment for pulmonary tuberculosis in Amhara region, Ethiopia. J Clin Microbiol. 2015;53(4):1301-9.

27. Asefa A, Teshome W. Total delay in treatment among smear positive pulmonary tuberculosis patients in five primary health Centers, southern Ethiopia: a cross sectional study. PLoS One. 2014;9(7):e102884.

28. Gebeyehu E, Azage M, Abeje G. Factors associated with Patient's delay in tuberculosis treatment in Bahir Dar City Administration, Northwest Ethiopia. BioMed Res Int. 2014:2014:701429.

29. Mesfin MM, Newell JN, Walley JD, Gessessew A, Madeley RJ. Delayed consultation among pulmonary tuberculosis patients: a cross sectional study of 10 DOTS districts of Ethiopia. BMC Public Health. 2009;9:53.

30. Huong NT, Vree M, Duong BD, Khanh VT, Loan VT, Borgdorff MW, et al. Delays in the diagnosis and treatment of tuberculosis patients in Vietnam: a cross-sectional study. BMC Public Health. 2007:7(1):110.

31. Sabawoon W, Sato H, Kobayashi Y. Delay in the treatment of pulmonary tuberculosis: a report from Afghanistan. Environ Health Prev Med. 2012; 17(1):53-61.

32. Takarinda KC, Harries AD, Nyathi B, Ngwenya M, Mutasa-Apollo T, Sandy C Tuberculosis treatment delays and associated factors within the Zimbabwe national tuberculosis programme. BMC Public Health. 2015;15(1):29.

33. Lin X, Chongsuvivatwong V, Lin L, Geater A, Lijuan R. Dose-response relationship between treatment delay of smear-positive tuberculosis patients and intra-household transmission: a cross-sectional study. Trans R Soc Trop Med Hyg. 2008;102(8):797-804

34. Gebeyehu E, Azage M, Abeje G. Factors associated with Patient's delay in tuberculosis treatment in Bahir Dar City Administration, Northwest Ethiopia. Biomed Res Int. 2014:2014

35. Hussen A, Biadgilign S, Tessema F, Mohammed S, Deribe K, Deribew A. Treatment delay among pulmonary tuberculosis patients in pastoralist communities in bale zone, Southeast Ethiopia. BMC Res Notes. 2012;5:320. 
36. Mohamed E, Abdalla S, Khamis A, Abdelbadea A, Abdelgadir M. Factors associated with patient delay in accessing pulmonary tuberculosis care. Sudan: Gezira State; 2009. p. 2013.

37. Saifodine A, Gudo PS, Sidat M, Black J. Patient and health system delay among patients with pulmonary tuberculosis in Beira city, Mozambique. BMC Public Health. 2013;13(1):559.

38. Yimer SA, Bjune GA, Holm-Hansen C. Time to first consultation, diagnosis and treatment of TB among patients attending a referral hospital in northwest, Ethiopia. BMC Infectious Diseases. 2014;14:19.

39. Kuznetsov VN, Grjibovski AM, Mariandyshev AO, Johansson E, Bjune GA. Two vicious circles contributing to a diagnostic delay for tuberculosis patients in Arkhangelsk. Emerg Health Threats J. 2014;7 10.3402/ehtj.v3407. 24909.

40. Valerie A. Paz-Soldan REA, Jones CD, Powell AR and Richard A. Oberhelman: patient reported delays in seeking treatment for tuberculosis among adult and pediatricTB patients andTB patients co-infected with HIV in lima, Peru: a qualitative study. FrontiersinPublicHealth | InfectiousDiseases. 2014; 2|Article281.

41. Verhagen LM, Kapinga R, van Rosmalen-Nooijens KAWL. Factors underlying diagnostic delay in tuberculosis patients in a rural area in Tanzania: a qualitative approach. Infection. 2010;38(6):433-46.

42. Chen CC, Chiang CY, Pan SC, Wang JY, Lin HH. Health system delay among patients with tuberculosis in Taiwan: 2003-2010. BMC Infect Dis. 2015;15: 491.

43. Pradhan A, Kielmann K, Gupte H, Bamne A, Porter JD, Rangan S. What'outliers' tell us about missed opportunities for tuberculosis control: a cross-sectional study of patients in Mumbai, India. BMC Public Health. 2010;10(1):263.

44. Belkina TV, Khojiev DS, Tillyashaykhov MN, Tigay ZN, Kudenov MU, Tebbens $J D$, et al. Delay in the diagnosis and treatment of pulmonary tuberculosis in Uzbekistan: a cross-sectional study. BMC Infect Dis. 2014;14(1):624.

45. Mohammad S, Alavi PB, Albagi A: Factors associated with delay in diagnosis and treatment of pulmonary tuberculosis. undishapur J Microbiol 2015; 8(3): e19238. DOl: 19210.15812/jjm.19238.

46. Ayé $R$, Wyss $K$, Abdualimova $H$, Saidaliev S. Patient's site of first access to health system influences length of delay for tuberculosis treatment in Tajikistan. BMC Health Serv Res. 2010;10(1):10.

47. Basnet R, Hinderaker SG, Enarson D, Malla P, Mørkve O. Delay in the diagnosis of tuberculosis in Nepal. BMC Public Health. 2009;9:236.

48. Behera BK, Jain RB, Gupta KB, Goel MK. Extent of delay in diagnosis in new smear positive patients of pulmonary tuberculosis attending tertiary care hospital. Int J Prev Med. 2013;4(12):1480-5.

49. Biya O, Gidado S, Abraham A, Waziri N, Nguku P, Nsubuga P, et al. Knowledge, care-seeking behavior, and factors associated with patient delay among newly-diagnosed pulmonary tuberculosis patients, Federal Capital Territory, Nigeria, 2010. Pan African Med J. 2014;18(Suppl 1)

50. Buregyeya E, Criel B, Nuwaha F, Colebunders R. Delays in diagnosis and treatment of pulmonary tuberculosis in Wakiso and Mukono districts, Uganda. BMC Public Health. 2014;14(1):586.

51. Cambanis A, Ramsay A, Yassin MA, Cuevas LE. Duration and associated factors of patient delay during tuberculosis screening in rural Cameroon. Tropical Med Int Health. 2007;12(11):1309-14.

52. Deponti GN, Silva DR, Coelho AC, Muller AM, Paulo de Tarso RD. delayed diagnosis and associated factors among new pulmonary tuberculosis patients diagnosed at the emergency department of a tertiary care hospital in Porto Alegre, South Brazil: a prospective patient recruitment study. BMC Infect Dis. 2013;13(1):538.

53. Jurcev-Savicevic A, Mulic R, Kozul K, Ban B, Valic J, Bacun-Ivcek L, et al. Health system delay in pulmonary tuberculosis treatment in a country with an intermediate burden of tuberculosis: a cross-sectional study. BMC Public Health. 2013;13(1):250.

54. Kansiime C, Kiwuwa SM, Levi M, Asiimwe BB, Katamba A. Health service delay among pulmonary tuberculosis patients presenting to a National Referral Hospital, Kampala, Uganda: a cross sectional study. Pan African Med J. 2013;15:84.

55. Li X, Jiang S, Li X, Mei J, Zhong Q, Xu W, et al. Predictors on delay of initial health-seeking in new pulmonary tuberculosis cases among migrants population in East China. PLoS One. 2012;7(2):e31995.

56. Maciel E, Golub J, Peres R, Hadad D, Fávero J, Molino L, et al. Delay in diagnosis of pulmonary tuberculosis at a primary health clinic in Vitoria, Brazil. Int J Tuberc Lung Dis. 2010;14(11):1403-10.
57. Maior ML, Guerra RL, Cailleaux-Cezar M, Golub JE, Conde MB. Time from symptom onset to the initiation of treatment of pulmonary tuberculosis in a city with a high incidence of the disease. J Bras Pneumol. 2012;38(2):202-9.

58. Makwakwa L, Sheu ML, Chiang CY, Lin SL, Chang PW. Patient and health system delays in the diagnosis and treatment of new and retreatment pulmonary tuberculosis cases in Malawi. BMC Infect Dis. 2014;14(1):132.

59. Mfinanga SG, Mutayoba BK, Kahwa A, Kimaro G, Mtandu R, Ngadaya E, et al. The magnitude and factors associated with delays in management of smear positive tuberculosis in Dar es salaam, Tanzania. BMC Health Serv Res. 2008; 8:158.

60. Nasehi M, Hassanzadeh J, Rezaianzadeh A, Zeigami B, Tabatabaee H, Ghaderi E. Diagnosis delay in smear positive tuberculosis patients. J Res Med Sci. 2012;17(11):1001-4.

61. Ngadaya E, Mfinanga G, Wandwalo E, Morkve O. Delay in tuberculosis case detection in Pwani region, Tanzania. A cross sectional study. BMC Health Serv Res. 2009;9:196.

62. Ngangro NN, Ngarhounoum D, Ngangro MN, Rangar N, Siriwardana MG, des Fontaines VH, et al. Pulmonary tuberculosis diagnostic delays in Chad: a multicenter, hospital-based survey in Ndjamena and Moundou. BMC Public Health. 2012;12(1):513.

63. Rabin A, Kuchukhidze G, Sanikidze E, Kempker R, Blumberg H. Prescribed and self-medication use increase delays in diagnosis of tuberculosis in the country of Georgia. Int J Tuberc Lung Dis. 2013;17(2):214.

64. Sendagire I, Van der Loeff MS, Mubiru M, Konde-Lule J, Cobelens F. Long delays and missed opportunities in diagnosing smear-positive pulmonary tuberculosis in Kampala, Uganda: a cross-sectional study. PLoS One. 2010; 5(12):e14459.

65. Woith WM, Rappleyea ML. Emotional representation of tuberculosis with stigma, treatment delay, and medication adherence in Russia. J Health Psychol. 2014;1359105314538349.

66. Yimer S, Bjune G, Alene G. Diagnostic and treatment delay among pulmonary tuberculosis patients in Ethiopia: a cross sectional study. BMC Infect Dis. 2005;5:112.

67. Li Y, Ehiri J, Tang S, Li D, Bian Y, Lin H, et al. Factors associated with patient, and diagnostic delays in Chinese TB patients: a systematic review and metaanalysis. BMC Med. 2013;11:156. http://www.biomedcentral.com/1741-7015/ 1711/1156.

68. Alavi SM, Bakhtiyariniya P, Albagi A. Factors associated with delay in diagnosis and treatment of pulmonary tuberculosis. Jundishapur J Microbiol. 2015;8(3).

\section{Submit your next manuscript to BioMed Central and we will help you at every step:}

- We accept pre-submission inquiries

- Our selector tool helps you to find the most relevant journal

- We provide round the clock customer support

- Convenient online submission

- Thorough peer review

- Inclusion in PubMed and all major indexing services

- Maximum visibility for your research

Submit your manuscript at www.biomedcentral.com/submit 